\title{
TOTAL PRODUCTIVITY IN THE AUSTRALIAN HOTEL INDUSTRY: ESTIMATING AND BOOTSTRAPPING MALMQUIST INDICES
}

\author{
A. GEORGE ASSAF* and FRANK WOGBE AGBOLA $\dagger$ \\ *Isenberg School of Management, University of Massachusetts-Amherst, Amherst, MA, USA \\ $\uparrow$ Newcastle Business School, Faculty of Business and Law, The University of Newcastle, Callaghan, Australia
}

\begin{abstract}
This article measures and decomposes the productivity of Australian hotels over the period 20042007, using a bootstrapped Malmquist index. The aim of this procedure is to seek out those determinants that explain the sources of productivity variation between Australian hotels. Two inputs and six outputs are used in the analysis, reflecting the operational characteristics of each hotel. The results indicate that most hotels in the sample experienced a significant increase in productivity, driven mainly by an increase in technology over the period analyzed. Factors that are found to be strong determinants of productivity include the location, size, and star rating of each hotel. Related market discussions of these findings as well as the policy implications of the study are provided.
\end{abstract}

Key words: Australian hotels; Small and medium enterprises (SMEs); Productivity; Malmquist; Bootstrap

\section{Introduction}

The Australian hotel industry has been traditionally dominated by small and medium enterprises (SMEs), which in comparison to large hotels face additional financial, technological, seasonality, and scale challenges (Barros \& Dieke, 2008; Bergin-Seers, 2000; Butler, 1994). In other industries such as manufacturing, computers, and services, the literature is rich with studies indicating that large firms are more profitable and efficient (Biggs, Shah, \& Srivastava, 1996; Haddad \& Harrison, 1993). A few studies in the hotel indus- try and other related areas have also reported similar findings (Barros \& Dieke, 2007; 2008).

The pressure on small and medium hotels has also recently intensified due to the financial crisis and the drop in international travel. In Australia, for instance, growth in visitor arrivals has slowed sharply, so much so that it is causing many small hotel operators great concern (IBISWorld, 2009). These trends have been the result of several factors, notably the strength of the Australian dollar, the increase in oil price, the decrease in household disposable income, the decrease in industry employment, and rapid technological changes. 
Australia's large hotel industry also faces challenges. Several large hotel groups have recently shifted their focus from Australia to expand into new emerging markets such as China and India, with some examples being Marriott International, Langham, Intercontinental, Windham Worldwide, and Accor. It is thus expected that there will be intense regional competition and a decline in revenues over the coming few years. The Australian Hotel Association (AHA) has recently stressed that the focus ahead should be on maintaining high occupancy and average room rates. This brings a need to maintain high performance in operations in order to attract future investors to the industry. Other important factors for the future survival of hotels are the need to develop marketing strategies, state of art operations, and excellent service quality.

In the literature, it is clearly established that formulating competitive strategies starts with an understanding of the measurement and performance of the hotel industry (Anderson, Fish, Xia, \& Michello, 1999; Anderson, Lewis, \& Parker, 1999; Barros, 2006). Equally important is the need to understand the factors that affect managerial efficiency. Traditionally, the literature on hotel performance has been restricted to the use of simple ratio methods that failed to provide a comprehensive measurement of the performance of the industry. This is because hotels operate in a complex setting driven by multiple and interlinked inputs and outputs. Solutions to these problems have appeared in the recent literature, mainly through the introduction of more advanced methodologies such as Data Envelopment Analysis (DEA) and Stochastic Frontier Analysis (SFA).

In the present article, we aim to introduce these advanced methods to the Australian hotel context. All the above-mentioned challenges facing the industry set a strong need to examine the performance of hotels in Australia in an attempt to propose some performance improvement strategies. This study also aims to explain the sources of productivity variation between Australian hotels. Several hypotheses are tested including the impact of size, location, and star rating on the performance of Australian hotels. In analyzing productivity, we also calculate how it has changed over time, so that we can provide a stronger linkage between the impact of the current trends and the performance of the industry. We achieve these objectives through the use of the Malmquist index, which is based on the DEA method. The estimation is also improved through the use of the bootstrap approach, which allows the construction of confidence intervals for the various Malmquist estimates. The statistical significance of the degree of productivity and efficiency changes can be tested, based on the results of the confidence intervals.

This article proceeds as follows. Section 2 presents a brief overview of the Australian hotel industry. Section 3 presents the review of literature on hotel industry performance. Section 4 provides a description of the methodology and data employed in the analyses. Section 5 reports and discusses the empirical results. Section 6 concludes by drawing some implications of the results for policy formulation and implementation in the Australian hotel industry.

\section{Overview of the Australian Hotel Industry}

The Australian hotel industry is an important part of the Australian economy, representing a total value added of around AUS $\$ 4.2$ billion dollars (Australian Bureau of Statistics, 2008). The industry is geographically spread across the various Australian states, deriving its demand mainly from the domestic market. The international market is also important for some states and represents up to $40 \%$ of the total customer demand. Among the different states, New South Wales has the largest share of the industry, mainly due to its strategic location and various attractions for the international market (IBISWorld, 2009). The state has also the largest share of hotel rooms, and strong representation by the international hotel chains. Other popular states include Victoria and Queensland, while smaller states such as Tasmania and the Northern Territory have generally a lower number of hotel rooms. In terms of size, the industry is generally dominated by small hotels, ranging in some cases between 5 and 15 rooms. The largest share of industry revenues belongs to fourstar hotels $(53 \%)$, while three or less star rating hotels account for around $25 \%$ of industry revenue, and five-star hotels for $22 \%$.

Similar to the tourism industry, the hospitality 
industry is sensitive to changes in the external environment. Recently, for example, the industry was strongly hit by the financial crisis, mainly due to the drop in household income, and the decline in international visitor arrivals including those from China, India, and many parts of Asia. On average, the industry witnessed a decline of revenues of around $2.3 \%$ in 2008-2009 in comparison to 2007-2008 (IBISWorld, 2009). Domestic tourism and investment in new hotels have also strongly declined. Future forecasts indicate that over the coming few years, the economic downturn will continue to affect the industry. Higher unemployment rates and lower rises in household disposable income are expected to affect the number of domestic tourists and international arrivals (Travel and Tourism in Australia, 2009). Within this declining market situation, price competition between hotels is expected to increase, reinforcing the need for high performance and careful operational strategies.

In the next section we outline, via a brief review of the literature, the reasons for and the nature of the shift in the estimation procedures being deployed to measure the sector's performance.

\section{Literature Review}

Several factors create complexities in measuring the productivity of the hospitality industry including its multiple input-output setting, as well as its exposure to the direct influence of the surrounding external environment. There are several studies which provide a comprehensive overview of the traditional productivity literature in the hospitality industry. In general, the most adopted methods were restricted to the single input-output ratio measure or other related techniques such as "yield management" or "breakeven room occupancy methods," which fail to provide a comprehensive and reliable measure of overall performance.

In contrast, recent studies have measured the performance of the industry using more robust multiple input-output techniques, such as Data Envelopment Analysis (DEA) and Stochastic Frontier Analysis (SFA). A detailed literature on the modern efficiency studies in the hotel context has appeared in several studies (Barros \& Dieke,
2008) and thus it will not be reiterated here. Some examples of DEA and stochastic frontier studies include Morey and Ditman (1995), Johns, Howcroft, and Drake (1997), Anderson et al. (1999), Anderson et al. (1999), Anderson, Fok, and Scott (2000), Brown and Ragsdale (2002), Reynolds (2003), Barros (2006), Wang, Hung, and Shang (2006), Reynolds and Thompson (2007), Chen (2007), Shang, Hung, Lo, and Wang (2008), and Barros, Botti, and Peypoch (2009). The key input and output variables used in these studies include the number of employees, labor cost, the number of rooms, room revenues, food revenues, and occupancy rate.

Most of these applications have focused on analyzing the efficiency of the hospitality industry in countries such as the US, Portugal, and Taiwan. Other studies have also tested the impact of some environmental variables such as size, location, and ownership on the efficiency of hotels. Similar to other industries, the impact of size was generally found to be a strong determinant of hotels' technical efficiency, with larger hotels enjoying a higher efficiency than smaller hotels. The impact of ownership was also described as important, especially when comparing the performance of independent vs. chain hotels. Recently, Barros and Dieke (2008) have also indicated that city located hotels are more efficient than non-city hotels.

This study aims to provide a further extension to the above literature by focusing on the efficiency analysis of Australian hotels. We also aim to provide a further validation of the impact of environmental variables on efficiency. The methodology used here is innovative in the hotel context, as most previous studies failed to provide any statistical properties of the productivity results. More detail about the methodology is provided in the following subsections.

\section{Methodology}

\section{The Malmquist Index}

The Malmquist index is used in this study to measure the total factor productivity (TFP) change for a particular hotel between two time periods, $t$ and $t+1$. The Malmquist index is defined using distance functions which describe the multi-input, multioutput production technology. It measures 
the TFP change between two data points by calculating the ratio of the distances of each data point relative to a common technology. Following Fare, Grosskopf, and Lovell (1994), the index can be calculated between two periods $t$ and $t+1$ as the geometric mean of the $t$ and $t+1$ indices:

$$
m_{0}^{t, i+1}=\left[\frac{d_{0}^{t}\left(\mathbf{y}^{i+1}, \mathbf{x}^{t+1}\right)}{d_{0}^{t}\left(\mathbf{y}^{t}, \mathbf{x}^{t}\right)} \frac{d_{0}^{i+1}\left(\mathbf{y}^{t+1}, \mathbf{x}^{t+1}\right)}{d_{0}^{i+1}\left(\mathbf{y}^{i}, \mathbf{x}^{t}\right)}\right]
$$

where $d_{0}^{t}\left(\mathbf{y}^{t+1}, \mathbf{x}^{t+1}\right)$ represents the distance from the period $t+1$ observation to the period $t$ technology. Improvements of productivity over time are signaled when $m_{0}{ }^{t, t+1}$ is larger than one, where declines in productivity are signaled when $m_{0}{ }^{t, t+1}$ is less than one. The index in equation (1) can also be further decomposed into two components: efficiency change and technological change as

$$
m_{0}^{t, i+1}=\underbrace{\frac{d_{0}^{t}\left(\mathbf{y}^{i+1}, \mathbf{x}^{t+1}\right)}{d_{0}^{t}\left(\mathbf{y}^{t}, \mathbf{x}^{t}\right)}}_{\text {Efficiency Change }}[\underbrace{\frac{d_{0}^{i}\left(\mathbf{y}^{t+1}, \mathbf{x}^{t+1}\right)}{d_{0}^{i+1}\left(\mathbf{y}^{t+1}, \mathbf{x}^{t+1}\right)} \frac{d_{0}^{t}\left(\mathbf{y}^{t}, \mathbf{x}^{t}\right)}{d_{0}^{i+1}\left(\mathbf{y}^{t}, \mathbf{x}^{t}\right)}}_{\text {Technological Change }}]^{1 / 2}
$$

where the first component in the above represents the efficiency change (i.e., change in the hotel location relative to the technology between the two periods) and the second component represents the technological change (i.e., change in technology location between the two periods). Note that it is possible to take the efficiency change measure in equation (2) and decompose it into scale and pure efficiency change components.

Thus, as indicated in equation (2), the estimation of the Malmquist index and its components requires the estimation of four distance functions: $d_{0}^{t}\left(\mathbf{y}^{t}, \mathbf{x}^{t}\right), d_{0}^{t+1}\left(\mathbf{y}^{t+1}, \mathbf{x}^{t+1}\right), d_{0}^{t}\left(\mathbf{y}^{t+1}, \mathbf{x}^{t+1}\right)$, and $d_{0}^{t+1}\left(\mathbf{y}^{t}, \mathbf{x}^{t}\right)$. DEA is usually the common method to estimate these distance functions. We do not provide details of the method here but these can be simply obtained from Coelli, Prasada Rao, and Battese (1998).

\section{The Bootstrap}

While the DEA approach to the estimation of the Malmquist index is simple, it is nonstatistical and thus fails to indicate whether the obtained productivity or efficiency changes are statistically sig- nificant. It is also well known from the literature that DEA's sensitivity to sampling variations might lead to misleading efficiency results. The present article accounts for these problems by using the bootstrap procedure developed by Simar and Wilson (1999). When applied to DEA, the bootstrap allows the construction of confidences intervals, and thus makes it possible to obtain statistical properties of the efficiency estimates and also perform some hypotheses testing. Simar and Wilson (1998, 1999) have also argued that the approach can be simply extended to obtain confidence intervals of the DEA-based Malmquist index. More technical details are provided by Simar and Wilson (1998, 1999). Monte Carlo evidence on the consistency of the approach is also provided in their article. In the case of the Malmquist index, the bootstrap must be performed in each time period, and consequently this might give rise to temporal correlation that needs to be taken into account. That is, low efficiency of a firm in one time period may increase the probability that the firm has also a low efficiency in the second time period, etc. Simar and Wilson (1999) ${ }^{1}$ correct for this problem by using a bivariate smoothing procedure.

\section{Data}

The input-output variables used in this study followed other studies in the literature. Due to the privacy act, the Australian Hotel Association (AHA) does not publish financial or operational data for its member hotels. For this reason, a questionnaire was sent via mail to 90 hotels $^{2}$ from three major hotel chains located across different states and territories in Australia. Responses were received from 34 hotels (response rate of $37.7 \%$ ), with the data gathered spanning the period 20042007. Due to inconsistencies of the data reported, only data for $31(31 \times 4=124$ observations $)$ hotels were employed in the final analysis. Table 1 provides yearly statistics of the data.

To estimate the Malmquist index we used two outputs and six inputs. The inputs include the total payroll in the room department, total payroll in other departments, the cost of food, cost of beverages, cost of maintaining rooms, and the number of rooms available (a proxy for the cost of capi- 
Table 1

Descriptive Statistics of the Data

\begin{tabular}{lrrrrrrrr}
\hline & $\begin{array}{r}\text { Rooms } \\
\text { Payroll }\end{array}$ & \multicolumn{1}{c}{$\begin{array}{c}\text { Other } \\
\text { Payroll }\end{array}$} & \multicolumn{1}{c}{$\begin{array}{c}\text { Food } \\
\text { Cost }\end{array}$} & $\begin{array}{c}\text { Bev. } \\
\text { Cost }\end{array}$ & $\begin{array}{c}\text { Rooms } \\
\text { Expenses }\end{array}$ & $\begin{array}{c}\text { Rooms } \\
\text { Available }\end{array}$ & $\begin{array}{c}\text { Room } \\
\text { Revenue }\end{array}$ & $\begin{array}{c}\text { F\&B } \\
\text { Revenue }\end{array}$ \\
\hline 2003-2004 & & & & & & & & \\
Mean & $1,061,530$ & $1,826,910$ & 559,017 & 254,860 & 480,601 & 58,533 & $4,816,157$ & $2,976,985$ \\
SD & 722,557 & $1,160,454$ & 355,130 & 272,806 & 404,557 & 34,801 & $3,525,107$ & $2,138,603$ \\
Median & 368,430 & 158,209 & 57,003 & 3,777 & 124,373 & 18,444 & 984,463 & 150,014 \\
Max & $3,801,333$ & $4,132,127$ & $1,362,412$ & $1,226,289$ & $2,126,771$ & 154,380 & $18,117,556$ & $6,934,171$ \\
Min & 824,250 & $1,469,766$ & 509,243 & 142,477 & 361,706 & 52,338 & $3,586,204$ & $2,321,993$ \\
2004-2005 & & & & & & & & \\
Mean & $1,094,865$ & $1,935,675$ & 554,886 & 243,542 & 492,755 & 56,987 & $4,878,336$ & $2,938,481$ \\
SD & 842,986 & $1,485,679$ & 400,258 & 280,906 & 420,272 & 34,449 & $3,771,837$ & $2,338,517$ \\
Median & 199,051 & 295,395 & 53,041 & 4,919 & 83,169 & 12,768 & 984,463 & 282,940 \\
Max & $4,530,516$ & $6,629,475$ & $1,487,225$ & $1,275,287$ & $2,162,855$ & 151,475 & $18,566,463$ & $7,957,893$ \\
Min & 810,319 & $1,389,285$ & 469,350 & 119,398 & 364,715 & 47,433 & $3,510,276$ & $1,993,144$ \\
2005-2006 & & & & & & & & \\
Mean & $1,126,625$ & $2,060,550$ & 591,145 & 257,317 & 516,458 & 58,803 & $5,463,972$ & $3,160,785$ \\
SD & 764,012 & $1,554,497$ & 387,489 & 279,125 & 422,108 & 33,922 & $3,954,214$ & $2,315,790$ \\
Median & 414,073 & 312,735 & 108,644 & 6,809 & 193,197 & 23,360 & $1,984,907$ & 367,920 \\
Max & $4,119,231$ & $7,678,782$ & $1,625,058$ & $1,316,808$ & $2,259,780$ & 151,475 & $19,425,478$ & $8,466,808$ \\
Min & 853,207 & $1,432,127$ & 478,547 & 154,191 & 373,673 & 47,433 & $3,867,322$ & $2,121,713$ \\
2006-2007 & & & & & & & & \\
Mean & $1,068,158$ & $2,017,373$ & 583,234 & 235,633 & 510,016 & 56,005 & $5,147,125$ & $3,009,388$ \\
SD & 538,527 & $1,578,720$ & 427,435 & 267,909 & 325,311 & 31,266 & $3,521,470$ & $2,350,349$ \\
Median & 218,373 & 321,952 & 103,913 & 9,159 & 81,697 & 8,556 & 848,663 & 357,866 \\
Max & $2,304,634$ & $7,599,207$ & $1,801,025$ & $1,194,163$ & $1,485,271$ & 132,495 & $14,395,646$ & $8,422,484$ \\
Min & 914,197 & $1,457,875$ & 480,620 & 120,662 & 386,848 & 47,433 & $3,821,268$ & $2,088,687$ \\
\hline
\end{tabular}

tal); while the outputs include the total room revenue and total food and beverage revenue. The data collection also involved gathering data on some hotel characteristics that are hypothesized to affect the productivity of hotels. These include the size, location (city vs. non-city), and the level of star rating of each individual hotel in the sample. This study follows Shang et al. (2008) and classifies hotels into two main categories, namely, small to medium hotels as those with less than 300 rooms, and large hotels as those with more than 300 rooms by using a dummy variable. A dummy variable was used to denote the location of hotels, and it takes the value of 1 for hotels located in the city area and 0 otherwise.

The level of quality of each hotel is measured indirectly by assessing the star rating of each hotel. Hotels with a higher star rating are usually expected to have better quality services and facilities, and thus be more attractive to tourists. Similarly, the hotels with city locations are usually more attractive to international tourists, and thus have an advantage when it comes to increasing their operational earnings.
Several studies have assessed the impact of size on the performance of firms, and in some cases the results are contradictory. In Table 2, we report the findings of some of these studies. It is generally claimed that large firms could be more efficient, because they could use more specialized inputs, coordinate their resources better, and reap the advantages of economies of scale (Alvarez \& Crespi, 2003). There are, however, some studies that argue that small firms could be more efficient, as they have flexible, nonhierarchical structures, and do not operate in a monopolistic environment, which generally creates a lower incentive to improve performance (Jovanovic, 1982). In the hotel industry, studies assessing the impact of size have also yielded different conclusions (Barros \& Dieke, 2008; Brown \& Ragsdale, 2002), especially when the results were tested across different countries. In fact, some studies argue that in the case of a developing economy, which is generally characterized by market failure caused by lack of financial and capital resources, firms may be more profitable if they increase their size or join a larger group to make up for the external market failures 
Table 2

Studies on the Impact of Size on Efficiency

\begin{tabular}{llll}
\hline Study & \multicolumn{1}{c}{ Industry } & \multicolumn{1}{c}{ Estimation Methodology } & \multicolumn{1}{c}{$\begin{array}{c}\text { Correlation With } \\
\text { Technical Efficiency }\end{array}$} \\
\hline $\begin{array}{l}\text { Haddad and Harrison (1993) } \\
\text { Biggs et al. (1996) }\end{array}$ & $\begin{array}{l}\text { Manufacturing sector } \\
\text { Food, wood, textile, and metal } \\
\text { sectors }\end{array}$ & $\begin{array}{l}\text { Fixed effect parametric method } \\
\text { Mean response production function }\end{array}$ & + \\
Brada et al. (1997) & Manufacturing sectors & Stochastic frontier model & + for most sectors \\
Hu and Schive (1997) & Manufacturing sectors & Stochastic frontier model & - for most sectors \\
Taymaz and Saatci (1997) & $\begin{array}{l}\text { Textile, cement, lime, plaster, } \\
\text { and motor vehicle }\end{array}$ & Stochastic frontier model & + for most sectors \\
Lundvall and Battese (2000) & Manufacturing sectors & Stochastic frontier model & + \\
Taymaz (2005) & Manufacturing sectors & Stochastic frontier model & + \\
Barros and Dieke (2008) & Hotels & DEA model & + \\
Barros and Dieke (2007) & Travel agents & DEA model & - \\
\hline
\end{tabular}

(Ghemawat \& Khanna, 1998; Khanna \& Palepu, 2000).

\section{Results and Discussion}

Table 3 reports the estimates of productivity, efficiency, and technology changes between 2004 and 2007. Table 4 reports the average changes between each consecutive year. All results were obtained using 2000 bootstrap replications. We do not report in the tables the confidence intervals for each measure, but we indicate whether the changes are significantly different from unity at the 5\% confidence level. ${ }^{3}$ Note that the confidence intervals are also available from the corresponding author.

Table 3 demonstrates that on average Australian hotels have experienced a significant increase in productivity over the period under analysis. Specifically, out of 31 hotels 16 (or more than $50 \%$ ) have experienced significant increases in their total productivity (expressed as "TFP" in Table 3) while 9 hotels have experienced a significant decrease in productivity. For the remaining 6 hotels, the productivity has not significantly changed. When investigating the other Malmquist index components in Table 3 , it is clear that the significant change in productivity is driven by mixed changes in efficiency and technology, however, in most cases the changes in total productivity were due to technological change. For instance, on the technological side, 17 hotels have experienced significant changes with 11 of them having estimates greater than unity, thus suggesting an increase in technological progress, while on the efficiency side only 10 hotels have experienced significant changes with 7 of them having estimates higher than unity, thus suggesting a failure of efficiency gains to keep pace with the technology gains.

Table 4 reports the average productivity changes between each consecutive year. It is evident that total productivity has increased over the years and reached its highest increase in 2006/2007. The same applies to the other Malmquist components, especially the technological changes. The individual hotel results for the changes in the Malmquist and its components can be obtained from the authors upon request.

Thus, the results displayed from both Tables 3 and 4 indicate that there was a productivity improvement in our sample of Australian hotels over the period analyzed (2004-2007). This increase in productivity might be partly explained in terms of some external trends. Over the period analyzed, the Australian hotel industry, for instance, benefited from high economic growth, which boosted household disposable income, business revenue, and profit growth (IBISWorld, 2009). Prices for Australian accommodation were also pushed up, as tourist numbers were growing faster than the additional accommodation stock. This led to some 
Table 3

Efficiency Change (EC), Technological Change (TC), and Total Factor Productivity Change (2004-2007)

\begin{tabular}{|c|c|c|c|}
\hline & $\mathrm{EC}$ & $\mathrm{TC}$ & TFP \\
\hline 1 & 1.0000 & $1.0710 *$ & $1.0710^{*}$ \\
\hline 2 & 1.0000 & 1.0290 & $1.0290^{*}$ \\
\hline 3 & 1.0000 & $1.0740 *$ & $1.0740 *$ \\
\hline 4 & 1.0000 & $1.2400 *$ & $1.2400 *$ \\
\hline 5 & 1.0000 & $1.1201 *$ & $1.1201 *$ \\
\hline 6 & 1.0040 & 0.9680 & 0.9710 * \\
\hline 7 & 0.9090 & $1.0400 *$ & $0.9450 *$ \\
\hline 8 & $1.0870 *$ & 1.0160 & $1.1040 *$ \\
\hline 9 & 1.0000 & $0.9330 *$ & $0.9330 *$ \\
\hline 10 & 1.0000 & $1.0750 *$ & $1.0750 *$ \\
\hline 11 & $0.9800 *$ & 1.0210 & 1.0010 \\
\hline 12 & 1.0000 & $0.9620 *$ & $0.9620 *$ \\
\hline 13 & 1.0000 & 1.0360 & $1.0360 *$ \\
\hline 14 & $0.9660^{*}$ & 0.9920 & $0.9580 *$ \\
\hline 15 & 1.0530 & 1.0190 & 1.0730 * \\
\hline 16 & 1.0000 & 1.0060 & 1.0060 \\
\hline 17 & 1.0000 & $0.8980 *$ & $0.8980 *$ \\
\hline 18 & $1.0410 *$ & $1.1210^{*}$ & $1.1680^{*}$ \\
\hline 19 & 0.9910 & 1.0140 & 1.0050 \\
\hline 20 & $1.1180^{*}$ & $0.9750 *$ & $1.0900 *$ \\
\hline 21 & $0.9140 *$ & $1.0640 *$ & $0.9730 *$ \\
\hline 22 & 1.0000 & $0.9830 *$ & 0.9830 \\
\hline 23 & 1.0000 & 0.9910 & 0.9910 \\
\hline 24 & 1.0000 & $1.1340 *$ & $1.1340^{*}$ \\
\hline 25 & $1.1220^{*}$ & 1.0390 & $1.1660 *$ \\
\hline 26 & 1.0000 & $0.9740 *$ & $0.9740 *$ \\
\hline 27 & $1.2840 *$ & 1.0180 & $1.3070 *$ \\
\hline 28 & 0.9720 & 0.9950 & $0.9670 *$ \\
\hline 29 & 1.0000 & 1.0110 & 1.0110 \\
\hline 30 & $1.1555^{*}$ & $1.1210 *$ & $1.2953^{*}$ \\
\hline 31 & $1.1369^{*}$ & $1.1210 *$ & $1.2744 *$ \\
\hline Average & 1.0007 & $1.0342 *$ & $1.0622 *$ \\
\hline
\end{tabular}

${ }^{*}$ Change is significant at the $5 \%$ confidence level.

upward pressure on prices, which in turn led to a value growth, most of which benefited the hotels segment. Continued low domestic airfares applied over most of this period, as did strong growth in interstate air travel and this assisted hotel bookings. Growth in international arrivals was also high, especially from countries like China, India,

Table 4

Yearly Productivity Changes

\begin{tabular}{lccc}
\hline Period & EC & TC & TFP \\
\hline $2004 / 2005$ & 1.0020 & 0.9890 & 0.9920 \\
$2005 / 2006$ & 0.9740 & 1.0300 & 1.0040 \\
$2006 / 2007$ & 1.0380 & 1.1120 & 1.1542 \\
\hline
\end{tabular}

and many other parts of Asia. Investment in new properties and refurbishment of existing hotels increased significantly, which continued to improve industry profit as room rates were able to rise (Australian Bureau of Statistics [ABS], 2009).

While external trends can impact hotel productivity, the variation in productivity can also be affected by the unique characteristics of each hotel. This article accounts for this important consideration by conducting a second stage regression on several covariates deemed to reflect the characteristics of the different hotels and thus explain the sources of productivity variation between Australian hotels. These include the size of hotel, star rating, and location of each hotel. Detailed justifications on the selection of each of these variables were provided in the Data section.

Table 5 provides the results of the second stage regression, expressed as follows:

$$
M_{i t}^{*}=\beta_{0}+\beta_{I} \text { Size }_{i t}+\beta_{2} \text { City }+\beta_{2} \text { Quality }+\varepsilon_{i t}
$$

where $M_{i t}^{*}$ is the total factor productivity, Size is the size of a hotel, City is a dummy variable that takes the values of 1 for hotels located in the city and zero otherwise, and Quality is the quality level of each hotel measured by its star rating.

Table 5 indicates that the productivity gain over the sample period is positively and significantly correlated with all three variables. Thus, productivity is lower at smaller hotels. This finding could be of particular importance in the Australian context, where the hospitality industry is dominated by small players. The Australian Hotel Association has on several occasions highlighted the challenges facing small hotels, especially in terms of the investments in product innovations or research and development. The situation is also more challenging for hotels that are not members of chains,

Table 5

Second Stage Regression (2000 Bootstrap Iteration)

\begin{tabular}{lccl}
\hline Variable & Coefficient & SE & $t$-Value \\
\hline Constant & 0.8720 & 0.1659 & $5.2561^{* *}$ \\
Star rating & 0.0076 & 0.0020 & $3.8001^{* *}$ \\
Size & 0.0065 & 0.0023 & $2.8260^{* *}$ \\
City & 0.0282 & 0.0123 & $2.2926^{*}$ \\
\hline
\end{tabular}


as they do not, in most cases, have their own website, or sufficient budgets for advertising. Similarly, the positive relationship between star rating and productivity does not bode well for the majority of Australian hotels which, according to the ABS (2007), have low star ratings, and are characterized by low occupancy rates. It is true that low star hotels break even at a lower percentage rate than five-star hotels; however, the Australian market is characterized by a large gap in occupancy between these two types of hotels, and this creates an area of concern (IBISWorld, 2009).

The location variable is found to be an important determinant of productivity in the Australian hotel industry. The results indicate that hotels located in city areas are more productive, confirming previous studies (Chen, 2007; Hwang \& Chang, 2003). The city hotels' higher productivity can be partially explained with reference to their attractiveness to international tourists and their greater product offerings. In Australia, smaller hotels are mostly concentrated in regional location which adds to the challenge of improving their sources of operational revenues.

Finally, looking at hotels in our sample, it was clear that most hotels that experienced efficiency decline were those operating at a smaller scale. Efficiency is usually related to management practice and employee skills (Coelli et al., 1998) and Australian SMEs, within and outside the hospitality sector, are characterized by low levels of educational attainment among managers and employees (Travel and Tourism in Australia, 2009). Further, very few SMEs, especially in the hotel industry, have strong links to Australia's vocational training institutions (e.g., TAFE) and apprenticeship schemes. The industries that are best supported by apprenticeship schemes in Australia are outside the hospitality sector and include construction, manufacturing, and wholesale and retail trade industries (IBISWorld, 2009).

\section{Conclusions}

This article had two main objectives: First, to measure and decompose the productivity of Australian hotels, and second, to explain the sources of productivity variation between Australian hotels. Several hypotheses were tested including the impact of size, location, and star rating on the performance of Australian hotels. From the results, it is clear that hotels in our sample experienced an increase in productivity over the period of study. The same applies to the other Malmquist components, especially the technological changes. Interestingly, the results indicate that larger hotels achieved higher productivity growth than smaller hotels. Other hotel characteristics which are found to be strong determinants of productivity growth are the hotel location and star rating. Such results suggest that in assessing or comparing the performance of hotels in Australia, it is important to take into account the characteristics of each hotel, as it seems the market is segmented along location lines.

Thus, the results of this study provide additional evidence of the productivity challenges facing small hotels in Australia. On the whole, small hotels are riskier than larger hotels, and they may face higher costs of capital, which trims their ability to raise it. Moreover, their managerial capacity may be lower than that of larger firms, again reducing their ability to raise capital. Hence, small hotels may gather fewer capital resources, including technology, than larger hotels. In general, small hotels pay lower wages than larger firms; therefore, smaller firms may be last in the queue for highly skilled labor. Hotels need skilled workers to embrace new methods and to get the best use from new investment. Consequently, SMEs may find themselves located towards the low end of a productivity/wage/skill scale.

The main limitation of the present study is its small sample size, which has implications for sampling error. Future studies are encouraged to obtain a large sample size in order to increase the generalizability of the results. Further, the present study could be complemented with qualitative research, such as case studies to elaborate further on the source of efficiency variation between Australian hotels, and develop a series of best practices that could be adopted by small hotels.

The results point to the economic vulnerability of small hotels and at the government level several strategies might be needed to improve their situation. In recent times, the Australian government has introduced a scheme that allows taxes on small business, including those in the tourism industry, 
to be cut by $\$ 435$ million over 4 years. The thrust of this policy is to reduce compliance costs, and increase access to small business' tax relief arrangements and capital gains tax concessions. Future government focus might also need to be on establishing an industry-led mentoring program focused on small to medium sized hotels to help them develop sound business training and human resource management strategies, and encourage innovation and research and development.

\section{References}

Alvarez, R., \& Crespi, G. (2000). Determinants of technical efficiency in small firms. Small Business Economics, 20, 233-244.

Anderson, R. I., Fish, M., Xia, Y., \& Michello, F. (1999). Measuring efficiency in the hotel industry: A stochastic frontier approach. International Journal of Hospitality Management, 18, 45-57.

Anderson, R. I., Fok, R., \& Scott, J. (2000). Hotel industry efficiency: An advanced linear programming examination. American Business Review, 18, 40-48.

Anderson, R. I., Lewis, D., \& Parker, M. E. (1999). Another look at the efficiency of corporate travel management departments. Journal of Travel Research, l(7), 267-272.

Australian Bureau of Statistics. (2007-2009). Tourist accommodation, Australia (Catalogue \#8635.0). Canberra, Australia: AGPS.

Barros, C. P. (2006). Analyzing the rate of technical change in the Portuguese hotel industry. Tourism Economics, 12, 325-346.

Barros, C. P., \& Dieke, P. U. C. (2007). Analyzing the total productivity change in travel agents. Tourism Analysis, 12, 27-37.

Barros, C. P., \& Dieke, P. U. C. (2008). Technical efficiency of African hotels. International Journal of Hospitality Management, 27, 438-447.

Barros, C. P., Botti, L., \& Peypoch, N. (2009). A framework to analyze productivity changes: Theoretical aspects and application to the Portuguese travel agencies sector. Tourism Analysis, 14, 325-335.

Bergen-Seers, S. (2000). Benchmarking small business performance: Barriers and benefits. In (ICSB) International Council for Small Business World Conference-Entrepreneurial SMEs-Engines for Growth in the Millennium, June 7-10, 2000, Brisbane, Queensland.

Biggs, T., Shah, M., \& Srivastava, P. (1996). Technological capabilities and learning in African enterprises (Case studies series). Washington: Regional Program of Enterprise Development (RPEP), World Bank.

Brada, J. C., King, A. E., \& Ma, C. Y. (1997). Industrial economics of transition: Determinants of enterprise efficiency in Czechoslovakia and Hungary. Oxford Economic Paper, 49, 104-127.
Brown, J. R., \& Ragsdale, C. T. (2002). The competitive market efficiency of hotel brands: An application of data envelopment analysis. Journal of Hospitality and Tourism Research, 26, 260-332.

Butler, R. W. (1994). Seasonality in tourism: Issues and problems. In A. V. Seaton (Ed.), Tourism-a state of the art (pp. 332-339). Chichester, UK: Wiley.

Chen, C. (2007). Applying the stochastic frontier approach to measure hotel managerial efficiency in Taiwan. Tourism Management, 28, 696-702.

Coelli, T., Prasada Rao, D. S., \& Battese, G. E. (1998). An introduction to efficiency and productivity analysis. Boston: Kluwer Academic Publishers.

Fare, R., Grosskopf, S., \& Lovell, C. A. K. (1994). Production frontiers. Cambridge: Cambridge University Press.

Ghemawat, P., \& T. Khanna. (1998). The nature of diversified business groups: A research design and two case studies. The Journal of Industrial Economics, 1, 35-61.

Haddad, M., \& Harrison, A. (1993). Are there positive spillovers from foreign direct investment? Evidence from panel data for Morocco. Journal of Development Economics, 42, 51-74.

Hwang S. N., \& Chang T. N. (2003). Using data envelopment analysis to measure hotel managerial efficiency change in Taiwan. Tourism Management, 24, 357-369.

Hu, M. W., \& Schive, C. (1997). A study on the productivity and efficiency of SMEs in Taiwan manufacturers. Taiwan Economic Review, 25, 1-26.

IBISWorld. (2009). Hotel Accommodation in Australiaindustry report (Report \#H5711). Melbourne, Australia.

Johns, N., Howcroft, B., \& Drake, L. (1997). The use of data envelopment analysis to monitor hotel productivity. Progress in Tourism and Hospitality Research, l(3), $119-127$

Jovanovic, B. (1982). Selection and the evolution of industry. Econometrica, 50, 649-670.

Khanna, T., \& Palepu, K. (2000). Is group affiliation profitable in emerging markets? An analysis of diversified Indian business groups. Journal of Finance, 55, 867891.

Lundvall, K., \& Battese, G. E. (2000). Firm size, age, and efficiency: Evidence from Kenyan manufacturing firms. Journal of Development Studies, 36, 146-163

Morey, R. C., \& Dittman, D. A. (1995). Evaluating a hotel GM's performance: A case study in benchmarking. Cornell Hotel Restaurant and Administration Quarterly, 36, 30-35.

Reynolds, D. (2003). Hospitality-productivity assessment using data envelopment analysis. Cornell Hotel and Restaurant Administration Quarterly, 44, 130-137.

Reynolds, D., \& Thompson, G. (2007). Multiunit restaurant productivity assessment using three-phase data envelopment analysis. International Journal of Hospitality Management, 26, 20-32.

Shang, J. K., Hung, W. T., Lo, C. F., \& Wang, F. C. (2008). Ecommerce and hotel performance: Three-stage DEA Analysis. The Service Industries Journal, 28, 529-540

Simar, L., \& Wilson, P. W. (1998). Sensitivity analysis of 
efficiency scores: How to bootstrap in nonparametric frontier models. Management Science, 44, 49-61.

Simar, L., \& Wilson, P. W. (1999). Estimating and bootstrapping Malmquist indices. European Journal of $O p$ erational Research, 115, 459-471.

Taymaz, E. (2005). Are small firms really less productive? Small Business Economics, 25, 429-445.

Taymaz, E., \& Saatci, G. (1997). Technical change and ef- ficiency in Turkish manufacturing industries. Journal of Productivity Analysis, 8, 461-475.

Travel and Tourism in Australia. (2009). Euromonitor travel and tourism reports. Washington, USA.

Wang, F., Hung, W. T., \& Shang, J. K. (2006). Measuring the cost efficiency of international tourist hotels in Taiwan. Tourism Economics, 12, 65-85. 